\title{
Review
}

\section{Levodopa in the Treatment of Parkinson's Disease: Current Status and New Developments}

\author{
David Salat ${ }^{\mathrm{a}}$ and Eduardo Tolosa $\mathrm{a}^{\mathrm{b}, *}$ \\ ${ }^{a}$ Universitat Autònoma de Barcelona, Barcelona, Spain \\ ${ }^{\mathrm{b}}$ Parkinson's Disease and Movement Disorders Unit, Neurology Service, Hospital Clínic, University of Barcelona; \\ Centro de Investigación Biomédica en Red sobre Enfermedades Neurodegenerativas (CIBERNED) Barcelona, Spain
}

\begin{abstract}
Levodopa, a dopamine precursor, is an effective and well-tolerated dopamine replacement agent used to treat Parkinson's disease (PD). Oral levodopa has been widely used for over 40 years, often in combination with a dopa-decarboxylase inhibitor (DDCI), which reduces many treatment complications, extending its half-life and increasing levodopa availability to the brain. Entacapone, a catechol- $O$-methyltransferase inhibitor, can also be used to improve the bioavailability of levodopa, especially when used in conjunction with a DDCI. During early-stage PD, treatment will depend on the severity of symptoms; if greater symptomatic effect is required then levodopa or dopamine agonists are usually the drugs of choice. The ability to remain employable or physically active is an important goal in younger patients, therefore, in some instances levodopa initiation should be considered early on, either as a monotherapy or in combination with other drugs. The clinical use of levodopa may eventually be limited by the development of various treatment-related complications, including response fluctuations, dyskinesia and psychiatric problems. Motor complications are related to the intermittent delivery of dopamine-replacing drugs to the brain. Triple combination of levodopa/carbidopa/entacapone available in a single tablet in multiple levodopa dose strengths offers flexibility and helps control response fluctuations. Recent developments in treatment with levodopa try to obtain continuous delivery with levodopa and include duodenal infusion of a levodopa/carbidopa, transdermal levodopa patch, and oral pro-levodopa. Levodopa remains the most potent dopaminergic therapy for PD.
\end{abstract}

Keywords: Levodopa/carbidopa, Parkinson's disease, wearing-off, dyskinesia, entacapone

\section{INTRODUCTION}

The core motor features of Parkinson's disease (PD) result from cell loss in the substantia nigra pars compacta $(\mathrm{SNc})$ and the degeneration of the nigrostriatal dopaminergic pathway [1-3]. Despite the increasing evidence that non-motor symptoms may precede the cardinal motor symptoms of PD [4], currently accepted clinical criteria for the diagnosis of PD require the identification of bradykinesia plus at least one of rigidity,

*Correspondence to: Eduardo Tolosa MD, FRCP, Neurology Service, Hospital Clinic, University of Barcelona, Villarroel 170, Barcelona 080036, Spain. Tel.: +34 9322757 85; Fax: +34 93227 57 83; E-mail: etolosa@clinic.ub.es. resting tremor or postural instability [5]. As such, diagnosis of PD is generally made when these symptoms become apparent, in the so called motor stage of the disease. This symptomatic period may be further subdivided into early and advanced phases; from a practical standpoint, the transition to the advanced phase is defined by an increase in symptom severity, the onset of motor complications of therapy (such as motor fluctuations or dyskinesias), and a progressive overshadowing of the core motor features by various non-motor symptoms [6].

Despite the fact that PD pathology can be widespread in the brain and affects a multitude of neurotransmitter systems, a good correlation exists 
Table 1

The introduction of levodopa into clinical neurology

George Cotzias, a neurologist, discovered the clinical usefulness of levodopa in 1967

The work that paved the way for this discovery was performed by Arvid Carrlson (striatum as the site for dopamine concentration and levodopa rescue of animals with reserpine-induced Parkinsonian symptoms) and Ohle Hornykiewicz (dopamine deficiency in the striatum in Parkinson's disease)

In 1961 Walther Birkmayer, at the insistence of Hornykiewicz, administered levodopa intravenously to patients with Parkinson's disease and observed a spectacular anti-akinetic effect

The US Food and Drug Administration approved levodopa for the treatment of Parkinson's disease in 1970

Cotzias's work opened up a new field with incredible consequences for people with Parkinson's disease, as well as changing

the understanding of treatment for neurodegenerative disorders

Table 2

Levodopa for the management of Parkinson's disease - key points

Levodopa has been the mainstay of therapy for Parkinson's disease since 1970. It is still the most efficacious drug for symptomatic treatment of Parkinson's disease

Levodopa is effective in the early stages of Parkinson's disease and remains efficacious as the disease progresses, with no intolerance developing with the passage of time

The main drawbacks of levodopa are dyskinesias and response fluctuations, which are, in part, related to its short half life and erratic gastric emptying

Dyskinesias can be disabling in a minority of people with Parkinson's disease, in particular in people with young onset Parkinson's disease

Steadying plasma levodopa levels (minimizing peaks and troughs) greatly reduces response fluctuations and is an important therapeutic objective

Several formulations of levodopa are available for oral administration:

Levodopa in combination with a dopa decarboxylase inhibitor

Levodopa in combination with a dopa decarboxylase inhibitor and a catechol-O-methyltransferase inhibitor

Slow-release levodopa in combination with a dopa decarboxylase inhibitor

Levodopa/dopa decarboxylase inhibitor dispersible tablets

The best bioavailability with oral levodopa is achieved by combining it with a dopa decarboxylase inhibitor and a catechol-

O-methyltransferase inhibitor (e.g. entacapone)

Steady plasma levodopa levels and continuous levodopa delivery to the brain can be achieved with continuous duodenal infusions

This strategy has been shown to be effective in people with disabling motor complications

Newer treatment strategies currently in development for continuous delivery of levodopa to the brain include transdermal

levodopa pro-drugs and oral levodopa in combination with a dopa decarboxylase inhibitor and newer catechol-Omethytransferase inhibitor

between severity of motor symptoms, particularly bradikynesia and rigidity and dopamine loss in the striatum and treatment has focused almost exclusively on the replacement of dopamine. Levodopa, a precursor to dopamine, gained Food \& Drug Administration approval for the treatment of PD in 1970. To date, levodopa remains the most effective and well tolerated dopamine-replacing agent [7], and contributes significantly to improvements in the quality of life of patients with PD [8,9]. The strong evidence supporting the use of levodopa means that it is currently considered the gold standard for the symptomatic treatment of the motor features of PD. This manuscript provides an overview of the use of levodopa in the management of PD, the current clinical practices regarding the initiation and optimization of levodopa, and the latest developments in levodopa therapy (see Tables 1 and 2 for some highlights related to levodopa development and clinical use).

\section{LEVODOPA THERAPY FOR PARKINSON'S DISEASE}

The efficacy of levodopa in PD has been widely recognized since its introduction over 40 years ago [10]. Previous concerns that levodopa may have toxic effects on the brain have now been mostly discarded, and it is currently accepted that, at least in terms of toxicity, there is no reason to delay the initiation of levodopa [11]. When taken orally, levodopa is quickly decarboxylated in the extracerebral tissues. Consequently, only a small proportion reaches the central nervous system. Since the advent of levodopa in the late $1960 \mathrm{~s}$, it has been routinely administered in combination 
with a dopa-decarboxylase inhibitor (DDCI), such as carbidopa [12] or benserazide [13]. This association reduces its peripheral conversion to dopamine, thereby minimizing the predominant side effects of circulating dopamine, such as nausea, vomiting and hypotension. Additionally, minimizing the peripheral degradation of levodopa extends its half-life and increases its availability to the brain, thereby prolonging the duration of its symptomatic effect [14]. During the late $1980 \mathrm{~s}$, controlled-release (CR) levodopa formulations were developed with the aim of improving levodopa delivery to the brain, and such CR tablets have been commercially available since 1991 . CR compounds consist of levodopa, in combination with either carbidopa or benserazide, embedded in a matrix designed to delay the release of the active ingredients, resulting in delayed absorption and more sustained plasma levodopa levels, as compared with regular levodopa [15, 16]. The bioavailability of CR-levodopa formulations is, however, somewhat unpredictable and generally lower than that with conventional levodopa, thereby necessitating a $\sim 30 \%$ increase in dose [17-19]. In addition, the longer symptomatic effect provided by these agents is sometimes counterbalanced by a longer time to onset of the clinical benefit - an observation that has led to the frequent combination of both conventional and $\mathrm{CR}$ preparations, particularly with regard to the first morning dose. Moreover, in patients experiencing dyskinesias, CR formulations of levodopa have been associated with prominent dyskinesia occurring at the end of the day [19]. Data regarding the degree of symptomatic control provided by each CR-levodopa formulation is conflicting: two studies reported better outcomes with CR formulations [20,21]; one study showed that CR formulations did not increase ON time without dyskinesia [22]; and results of a fourth study did not allow for robust conclusions to be drawn [23]. One long term study [24] failed to demonstrate a significant decrease in the rate of development of motor complications.
Another method for improving the bioavailability of plasma levodopa and delivery to the brain is to inhibit peripheral metabolism of levodopa via the catechol$O$-methyltransferase (COMT) pathway. Entacapone, a COMT inhibitor that has been clinically available since 1999, has been shown to enhance the transportation of levodopa across the blood-brain barrier and its conversion to dopamine $[25,26]$. This results in a $\sim 30 \%$ increase in the bioavailability of the drug. From a clinical perspective, dual inhibition of both COMT and DDC pathways results in a significant increase in daily ON time and a corresponding decrease in OFF time [27-30]. Increasing the bioavailability of levodopa with co-administration of COMT inhibitors, however, is also associated with an initial increase in dyskinesia that can generally be controlled with adjustments in the doses of levodopa. A recent clinical trial in early-stage untreated patients has shown that addition of entacapone to levodopa/carbidopa therapy does not reduce the development of dyskinesias [31]. Although another COMT inhibitor, tolcapone, has been shown to be more effective than entacapone [32], its association with an increased risk of potentially fatal hepatotoxicity has limited its clinical use to patients who do not respond to entacapone [33]. Although its clinical potential is still being evaluated in a phase III clinical trial, preliminary data suggest that the pharmacokinetic profile of the novel COMT inhibitor opicapone may allow for a once-daily administration [34].

The therapeutic dose of levodopa is variable and the majority of patients initially respond well to doses of $300-600 \mathrm{mg} /$ day. A lack of responsiveness to levodopa (evaluated after an 8-week treatment of at least $1000 \mathrm{mg} /$ day combined with a DDCI) is usually indicative of an alternative diagnosis, such as multiple system atrophy or progressive supranuclear palsy. When increasing levodopa dose, it is important that this is done both gradually and slowly in order to minimize the risk of dopaminergic side effects. Nevertheless, the presence of central side effects of levodopa, includ-

Table 3

Phenomenology of motor fluctuations

\begin{tabular}{ll}
\hline Motor state & Description \\
\hline Wearing-OFF & $\begin{array}{c}\text { Re-emergence of parkinsonian symptoms (either motor or non-motor) before the following scheduled treatment } \\
\text { dose } \\
\text { Worsening of motor function occurring prior to the onset of beneficial effect of a given levodopa dose } \\
\text { Cuper-OFF }\end{array}$ \\
$\begin{array}{l}\text { Clinically significant parkinsonism preceding the administration of the first daily treatment dose (equivalent to } \\
\text { wearing-off of the last dose of the previous day) }\end{array}$ \\
$\begin{array}{l}\text { Significantly prolonged time to experience improvement of parkinsonian symptoms after a given treatment dose } \\
\text { Dose failure (no ON) }\end{array}$ & $\begin{array}{l}\text { Lack of improvement of parkinsonian symptoms after a given treatment dose, despite its correct administration } \\
\text { Rnpredictable ON/OFF }\end{array}$ \\
\hline
\end{tabular}


ing somnolence, dyskinesia, mood changes or, rarely, a worsening in parkinsonism, can be used to demonstrate adequate absorption and delivery of levodopa in patients who do not respond to a given daily dose of levodopa.

\section{Motor complications associated with levodopa treatment}

As with the other available antiparkinsonian drugs, however, the clinical use of levodopa may eventually be limited by the development of various treatment-related complications, which include response fluctuations (summarized in Table 3), dyskinesias and psychiatric abnormalities.

\section{Response fluctuations and dyskinesias}

At the beginning of treatment, levodopa administered three times per day is associated with a long-duration response where symptoms are adequately controlled throughout the day. With time, however, this long-duration response becomes less marked, the duration of symptomatic effects of levodopa become shorter, and symptom control becomes dependent on the presence of adequate plasma levodopa levels. Plasma levodopa levels oscillate between peaks and troughs and are frequently erratic, reflecting the short half-life (90 minutes or less) and often irregular absorption of the drug. Oscillations in motor symptoms tend to correlate with oscillations in plasma levodopa levels $[35,36]$ and require frequent adjustments to the dosage regimen. Wearing-off, where symptoms of PD re-emerge before the next dose of levodopa is due, is associated with deep troughs in plasma levodopa. At the same time, dyskinesias, which consist of hyperkinetic involuntary movements of varying intensity and type, frequently occur. Dyskinesias usually appear during maximal plasma concentrations of levodopa (peak-dose dyskinesias), but may also occur at the beginning and end of a dose cycle (diphasic dyskinesias) [35]. A third type of dyskinesia related to chronic levodopa treatment is known as OFF-period dystonia; this commonly affects the foot and can be rather painful, tends to occur early in the day and can be precipitated by anxiety or attempts to walk [37]. Unlike peak-dose dyskinesias that can occur early on, OFF-period dystonia tends to occur after months or years of chronic levodopa treatment [38].

In patients with motor fluctuations, non-motor problems associated with the OFF periods are now usually recognized, and they may cause significant distress [39, 40]. In one study, all patients who had motor fluctuations also experienced at least one non-motor problem during OFF phases [39]. The non-motor symptoms most frequently reported during OFF periods include anxiety, drenching sweats, slowness of thinking, fatigue, akathisia, irritability, pain and hallucinations. In another study, patients reported tiredness as the most frequent non-motor symptom. Dopaminergic mechanisms are important in non-motor fluctuations, and they can improve with optimization of dopaminergic therapies.

The pathophysiology of levodopa associated response fluctuations is complex and yet incompletely understood. Progressive cell loss in the SNc hinders levodopa uptake as well as its metabolism to dopamine and storage in presynaptic terminals [41, 42]. In this situation, striatal dopamine levels are increasingly dependent on the amount of levodopa that reaches the brain. Given the short plasma half-life of levodopa that requires its administration in repeated doses throughout the day, stimulation of dopamine receptors becomes intermittent [43]. In animal experiments, pulsatile levodopa stimulation of spiny neurons in the caudate-putamen or putamen nucleus (depending, respectively, on whether rodent or primate species are being used) results in the up-regulation of intracellular messengers involved in the function of $\gamma$-aminobutyric acid-ergic efferents and, finally, alteration in the pattern of firing and synchronization of different structures in the basal ganglia [44, 45]. As shown in different animal models, some of these changes occur only if levodopa administration is pulsatile, and they may even be reversed by continuous dopaminergic stimulation [46]. Consequently, the hypothesis has been put forward that levodopa-associated motor complications, and dyskinesias in particular, may be caused by such intermittent or pulsatile stimulation of striatal dopamine receptors linked to intermittent levodopa delivery to the brain.

Levodopa dose appears to be a driving factor for the development of motor complications. In the Earlier versus Later Levodopa Therapy in Parkinson Disease (ELLDOPA) trial, wearing-off and dyskinesia occurred in 29.7 and $16.5 \%$ of patients, respectively, in de novo patients receiving $600 \mathrm{mg} /$ day of levodopa. In contrast, the incidence of dyskinesias and wearing-off in those receiving smaller doses of levodopa (150 or $300 \mathrm{mg} /$ day) was considerably lower, particularly for dyskinesias, for which the rate was similar to that of the placebo arm at the lower doses [47]. Age at disease onset also appears to have an important impact on motor complications. In young-onset PD, dyskinesias 
occur in about $94 \%$ of cases after 5 years of levodopa treatment $[48,49]$.

The incidence of motor complications is widely described in the literature. In a meta-analysis of published prospective studies, the risk of dyskinesias and motor fluctuations after 4-6 years of levodopa treatment was found to be around 40\% [50]. In addition, a study by Stacy et al. 2005 has shown that response fluctuations may be an early phenomenon when subtle and non-motor signs are also considered [40].

\section{Neuropsychiatric complications}

Other complications of levodopa include neuropsychiatric problems such as depression, confusion, hallucinations and sleep disorders. Such symptoms are thought to reflect, at least in some patients, the progression of the cerebral lesions to involve limbic structures and the cerebral cortex. Psychiatric complications occur in less than $5 \%$ of de novo patients on levodopa monotherapy [51]. However, hallucinations and psychosis from levodopa tend to be less pronounced than with other antiparkinsonian agents, and levodopa is typically the drug of choice to treat motor disabilities in PD patients with dementia or hallucinations.

Patients on dopamine replacement therapies may experience various impulse control disorders [52]. The DOMINION study found an overall prevalence of $13.6 \%$ in their study population, but levodopa (exclusively when taken in the higher dose range) was rarely associated with their occurrence [53]. Reports of impulse control disorders with levodopa monotherapy focus almost exclusively on pathological gambling [54] and hypersexuality [55]. Levodopa has also been implicated in the development of an unusual constellation of symptoms collectively termed dopamine dysregulation syndrome [56]. The condition is thought to result largely from sensitization of neural pathways caused by pulsatile stimulation of the nucleus accumbens and the prefrontal cortex [57]. Its frequency has been estimated to be 3-4\% [58], but these figures may be an underestimation, as the mildest cases are rarely diagnosed. Several risk factors, including a noveltyseeking personality, a history of mood disorders or alcohol dependence, have been identified [59]. Patients develop a craving for the drug and increase the dose of antiparkinsonian agents well above what is needed for adequate control of the motor features of the disease. Mood and behavioural disturbances (including any of the impulse control disorders) are the remaining features of this condition. Punding refers to a charac- teristic behavioural feature at times associated with the dopamine dysregulation syndrome. Its prevalence has been estimated to be about $1.5 \%$ [60]. Patients engage in repetitive and seemingly purposeless activities (usually examining, sorting or dismantling objects) for hours. Patients usually have poor insight of developing these complications and seldom perceive their situation as problematic. As a consequence, medical attention is usually sought by relatives and not the patients themselves. Management includes the reduction in levodopa dose (dopamine agonists may be required to compensate for the decrease in dopaminergic stimulation). Most patients, however, will be reluctant and poorly compliant with this strategy. If this strategy fails, amantadine and quetiapine have been reported to be helpful in this condition [61]. Deep brain stimulation (DBS) has met with mixed results, as both improvement and worsening of this symptom complex has been reported to occur [62].

\section{INITIATING LEVODOPA IN EARLY-STAGE PARKINSON'S DISEASE}

Medications available to manage PD symptoms in the early stages include the dopaminergic agents, such as levodopa, dopamine agonists and monoamine oxidase B (MAO-B) inhibitors, as well as amantadine and anticholinergic agents. The efficacy and safety of these various drugs have been reviewed extensively and the reader is referred to the National Institute for Health and Clinical Excellence (NICE), the European Federation of Neurology guidelines and the MDS Evidence Based Review for detailed information [63-67]. When symptomatic treatment is initiated, the choice of drug will depend in part on the severity and functional consequences of the existing symptoms.

When a significant symptomatic effect needs to be achieved, levodopa or dopamine agonists constitute the drugs of choice. Dopamine agonists have been widely used as initial therapy because of their symptomatic effect and because they have been shown to reduce the risk of motor complications when compared with levodopa. However, clinical trials have shown that about $50 \%$ of patients initiated on dopamine agonist monotherapy required supplemental levodopa within 2 years after initiation in order to maintain symptom control. In addition, long-term follow-up phases of these trials have shown that initiating treatment with a dopamine agonist does not reduce the risk of developing disabling motor complications [68, 69].

Since the risk of developing motor complications is considerably greater in patients with a younger age at 
onset, starting treatment with a dopamine agonist is considered justified, and is frequently implemented, in patients with an early onset of motor symptoms [70]. There is no general agreed-upon cut-off age for starting dopamine agonist or levodopa as the initial treatment. Most treating physicians would delay initiation of levodopa and start with a dopamine agonist or another antiparkinsonian agent in patients aged 60 years or below. Dopamine agonists, on the other hand, can cause behavioural side effects such as impulse control disorders and postural hypotension, even in early stages of treatment, and more commonly in elderly patients and those with cognitive impairment [71]. The ability to remain employable or physically active is an important goal in young patients. Consequently, while these young onset patients have a higher risk for motor complications, in some instances levodopa initiation should be considered early on, either as a monotherapy or in combination with other drugs.

When given to de novo patients, levodopa significantly improves the classic motor symptoms and is generally well tolerated. The ELLDOPA trial in treatment-näve patients with PD showed a dose-dependent improvement in motor scores with levodopa, and a lower Unified Parkinson's Disease Rating Scale (UPDRS) scores after a 2-week washout period compared with patients receiving placebo, after 6 months of treatment [47]. Early side effects include nausea (which can be improved with domperidone) and, rarely, orthostatic hypertension or neuropsychiatric problems such as depression, hallucinations or somnolence. No special benefit has been shown for initiating levodopa therapy with CR formulations [24] or with a levodopa/carbidopa plus entacapone [31]. Although entacapone increases the central bioavailability of levodopa to a greater extent than does carbidopa alone [72], this combination is not currently considered the treatment of choice in de novo or stable patients.

Recent studies have shown that the drugs used for the treatment of motor symptoms can influence some nonmotor manifestations of PD. Such proposed effects sometimes drive the selection of the drugs used in the initial stages. Pramipexole, for example, may have antidepressant properties beyond its effect upon motor symptoms [73]. Levodopa's effects upon non-motor symptoms, such as cognition or autonomic symptoms, are generally mild; however, it can improve sleep quality [74], rapid eye movement behaviour disorder [75, 76] and central pain [77]. In a recent study in early untreated PD patients, fatigue progressed less in lev- odopa treated patients [78]. The initiation of levodopa treatment has been shown to improve both anxiety and depression in PD patients [76, 79]. The significance of this observation, however, is not clear, as it could reflect not a true effect on the mood disturbances, but result from the improvement it causes on the motor features of the disease. Additionally, the emergence of affective symptoms upon levodopa treatment initiation (and their remission with drug withdrawal) has been reported [80]. In a 3-month prospective study [81], levodopa improved the overall cognitive status of PD patients, although not every cognitive domain was found to be equally affected (attention, reaction time and accuracy improved, while verbal attention and memory did not). The complex relationship between levodopa therapy and cognitive function in PD patients, may be further exemplified by conflicting reports on its effect on executive functions: a beneficial effect [82], a variable effect [83], and no significant effect [84] have all been published. Additional studies are needed to confirm and extend these effects of levodopa upon non-motor symptoms.

\section{OPTIMIZING LEVODOPA THERAPY IN ADVANCED-STAGE PD}

Motor complications associated with therapy occur frequently in advanced PD and can be the source of major disability [85]. As motor complications are thought to result in part from oscillations in plasma levodopa, current strategies for managing motor complications focus on maintaining stable concentrations of plasma levodopa within the therapeutic window (above the threshold for improvement of parkinsonian symptoms, and below the threshold for the development of dyskinesia). From a clinical perspective, the desired outcome is an increase in total daily $\mathrm{ON}$ time without disabling dyskinesia. However, this may become increasingly challenging, as the therapeutic window typically narrows as the disease progresses and levodopa is erratically absorbed from the gastrointestinal tract [86]. The sections below provide an overview of the current management strategies according to the type of motor complication.

\section{Wearing-off}

With advancing PD, most patients receiving conventional immediate-release preparations of levodopa require modifications to their levodopa doses in order 
to retain symptomatic control as the duration of effect of each dose becomes progressively shorter. Wearingoff is a considerable problem for patients receiving levodopa, with more patients describing this complication as a greater challenge of levodopa therapy than dyskinesia $[87,88]$. Optimization of treatment in this circumstance depends on the degree of control of parkinsonism as well as the presence or risk of dyskinesias. Modifying the dosing of conventional levodopa is a common strategy and can provide short-term benefits. In theory, fragmentation of total daily levodopa intake into lower and more frequent doses should provide more consistent plasma levodopa levels, and so more consistent symptom control. However, this strategy is frequently not helpful, since lower doses of levodopa do not improve the motor symptoms to the same extent as higher doses. Pharmacokinetic data suggest that peaks and troughs remain with dose fractionation, and symptoms of wearing-off may persist owing to suboptimal levodopa exposure [89]. In patients whose symptom control is adequate and dyskinesias are either not present or mild, one may also consider increasing the amount of a given levodopa dose (or doses) at the time of the day when wearing-off is most bothersome. However, it must be noted that such a strategy is likely to increase the risk of dyskinesias and subtherapeutic troughs may still occur [89].

Among the motor complications associated with levodopa therapy and disease progression early morning akinesia, which refers to the occurrence of clinically significant parkinsonism preceding the administration of the first daily dose of dopamine replacement agents, has been recently identified as a significant source of discomfort by $55.4 \%$ of 6351 respondents of an anonymous survey carried out among German PD patients [90]. A supplemental dose of levodopa taken upon awakening has been proven to be beneficial in this circumstance, with its effect shown to reach clinical significance within 15-75 minutes after drug ingestion [91].

In patients with severe recurrent OFF periods, levodopa may need to be administered up to every 2 hours during the waking day (occasionally with additional doses during the night), and the total daily requirement of the drug could be in the range of $2000 \mathrm{mg}$. The increasing complexity of the medication schemes, however, may lead to reduced therapeutic adherence [92]. If symptom control remains suboptimal after adjustment and optimization of levodopa treatment, other agents (either dopamine agonists or MAO-B inhibitors) may be added. In this situation, however, dopamine-related side effects may be induced or aggra- vated, and a reduction in the dose of levodopa is sometimes required.

As mentioned above, although CR-levodopa formulations were developed to provide more consistent delivery of levodopa, results from clinical trials in patients with motor fluctuations have demonstrated conflicting results compared with immediate-release levodopa formulations [15, 16, 20-22, 93]. While these levodopa formulations may benefit certain patients, irregular gastric absorption and competition with amino acids make achieving a predictable drug response difficult.

The addition of entacapone to each dose of standardrelease levodopa has been shown to significantly increase the bioavailability of levodopa and reduce the troughs in plasma levodopa concentrations compared with conventional levodopa/carbidopa therapy [94] and to improve wearing-off. Four 6-month, randomized, controlled studies have evaluated the efficacy and tolerability of levodopa/DDCI and entacapone versus levodopa/DDCI and placebo treatment in patients with motor fluctuations [25-29]. In the entacapone group, mean daily ON-time was increased by around 1 hour compared with the group receiving placebo, and UPDRS motor and activities of daily living scores were significantly decreased. An increased incidence of dyskinesias with levodopa/DDCI and entacapone was observed, but in general could be managed by a reduction in the levodopa dosage [25-29]. The most frequent adverse events associated with levodopa/DDCI and entacapone therapy are chromaturia (harmless urine discolouration), nausea, diarrhoea, constipation and dizziness [25-28, 94].

The triple combination preparation of levodopa/carbidopa/entacapone (LCE) is available as a single tablet in multiple levodopa dose strengths which facilitates a low-dose, gradual titration of levodopa. At the pharmacokinetic level, manipulation of the dosing strategy of LCE, by using for example higher doses in the morning and lower ones at later points during the day, avoids the accumulation of levodopa towards the end of the day without significantly lowering the trough value of plasma levodopa [95]. The simplicity of the dosing regimen may also influence treatment adherence [96].

A recent pharmacokinetic study has also evaluated the potential of LCE for control of night-time symptoms [97]. The results of the Phase I trial demonstrated that LCE $200 \mathrm{mg}$ provides a superior pharmacokinetic profile to that of CR-levodopa/carbidopa $200 / 50 \mathrm{mg}$, when administered either as a single evening dose or as a three-times-daily dosing regimen [98]. 


\section{Delayed ON and dose failure}

In later stages of PD, some doses may take longer to become effective (delayed $\mathrm{ON}$ ), and some doses may be barely or not effective at all (dose failure). These complications are generally regarded as the consequence of erratic drug absorption, and competition of levodopa with other amino acids for the neutral amino acid transport system (involved in the absorption of the drug from the proximal gastrointestinal tract and in crossing the blood-brain barrier). When present, delayed ONs and dose failures require the optimization of LD treatment as discussed above. In addition, simple dietary recommendations, such as chewing the tablets instead of swallowing them and taking the medication on an empty stomach (45 minutes before meals) and with carbonated beverages, has been reported to lead to a quicker and often more predictable onset of action with each dose. Dietary protein restriction has also been shown to provide a more stable response to levodopa therapy, but its recommendation should be made with caution, as it may contribute to malnutrition in this patient population. If the previous measures turn out to be ineffective, rescue with short-acting agents (soluble levodopa or subcutaneous apomorphine) remains an option. This last strategy, however, should be used sparingly owing to its potential association with neuropsychiatric complications.

\section{Unpredictable motor fluctuations}

This complex clinical situation may be viewed as the coexistence of wearing-off, delayed ONs and dose failure in a given patient. As such, its management requires a combination of the strategies proposed for the control of each one of these complications. Given its fitful nature, tailoring the treatment to a particular patient's needs is often difficult and requires expertise, sound clinical judgement and patience. If the adjustment of orally administered drugs does not result in significant symptom control, and the patient remains functionally impaired, alternative therapies (continuous duodenal infusion of levodopa gel, subcutaneous apomorphine pump or DBS) may be considered.

\section{Dyskinesia}

As opposed to the previous complications, dyskinesia may be more worrisome to caregivers, family members and acquaintances than to the patients, and treatment should be considered only if they signif- icantly impact daily functioning or are a source of significant social embarrassment. Any attempt to manage dyskinesia must take into account the temporal relationship of dyskinesia to drug intake (see Fig. 2). Peak-dose dyskinesia is usually responsive to the redistribution of the total daily levodopa intake into more frequent but smaller doses, but a reduction in the total dose of levodopa (or that of adjunctive therapies such as dopamine agonists, COMT or MAO-B inhibitors) is sometimes required. However, both the redistribution and reduction of the previous treatment may result in a worsening of parkinsonian symptoms, and it is advisable to make the reductions as small as possible, in order to balance the treatment of dyskinesia with the management of wearing-off. Whenever its prescription is possible, a dopamine agonist may improve the clinical status and allow for a further reduction in the dose of levodopa (and, thus, better control of the dyskinesias). If the previously described measures fail, specific treatment with amantadine $[99,100]$ or clozapine [101] may be tried. Isolated reports suggest that quetiapine may also be used [102], although its effects were found to be mild. Patients with non-responsive dyskinesias may be considered for any of the available continuous dopaminergic therapies or DBS. Moreover, the intervention over several non-dopaminergic systems (such as glutamate, serotonin, noradrenalin, adenosine, histamine or acethylcholine) for treating these motor complications [103] is currently being evaluated.

The treatment of diphasic dyskinesias is another of the clinical challenges posed by advanced PD. Treatment modification, as described for peak-dose dyskinesias, may in fact worsen biphasic dyskinesias, and the subcutaneous administration of apomorphine immediately preceding an ON/OFF state transition may be the only suitable alternative. The strategies outlined for the management of wearing-off and unpredictable ON/OFF fluctuations apply to the treatment of OFF-period dystonia. Although the management of refractory cases has not been recently addressed, some articles have suggested that they may occasionally benefit from lithium [104], baclofen or the injection of botulinum toxin [105].

\section{RECENT DEVELOPMENTS IN TREATMENT WITH LEVODOPA}

Once wearing off develops it can be ameliorated by smoothing out plasma levodopa levels and, furthermore, the hypothesis has been put forward that 


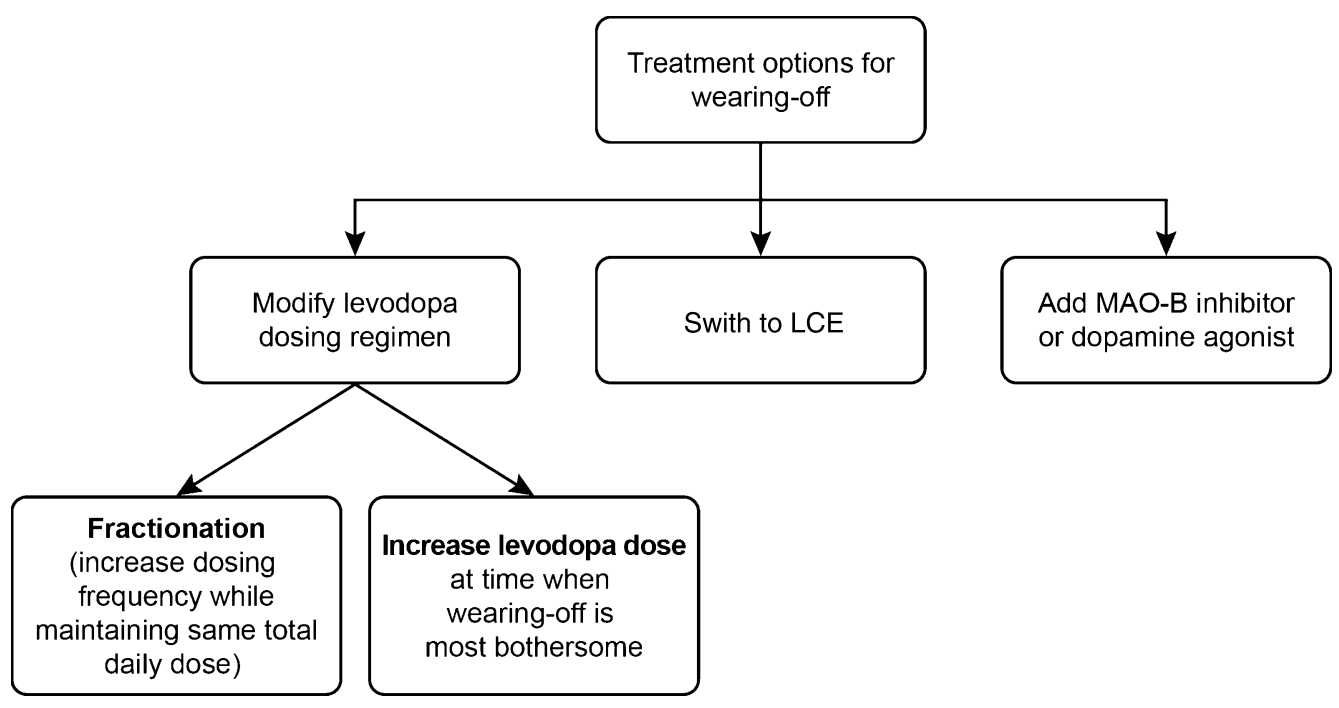

Fig. 1. Pharmacological treatment options for patients with wearing-off. COMT=catechol-O-methyl transferase; LCE=levodopa/ carbidopa/entacapone; MAO-B = monoamine oxidase-B.

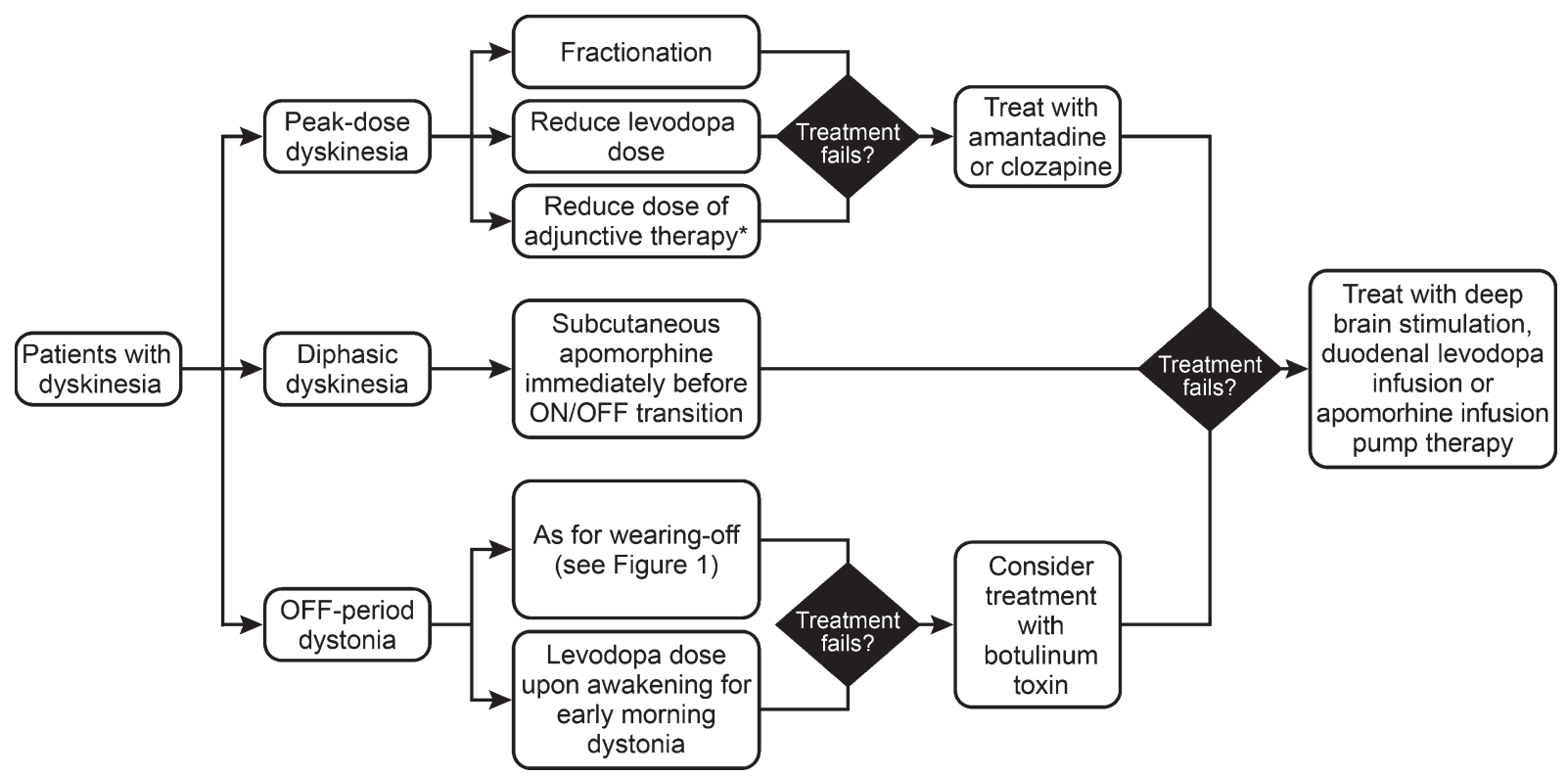

Fig. 2. Schematic diagram for treatment optimization in patients with dyskinesias. *Includes adjunctive catechol- $O$-methyl transferase inhibitors, monoamine oxidase B inhibitors, dopamine agonists.

pulsatile-intermittent administration of levodopa may play a significant role in the development of motor complications. Accordingly strategies are being developed to obtain continuous drug delivery with levodopa itself.

The duodenal infusion of a water-soluble suspension of levodopa and carbidopa in methylcellulose (levodopa/carbidopa intestinal gel, LCIG), has been found to be successful for achieving nearly stable plasma concentrations of levodopa [106-109]. LCIG is commercially available in Europe, under the trade name Duodopa ${ }^{\mathrm{TM}}$, as $100 \mathrm{~mL}$ cartridges containing a $20 \mathrm{mg} / 0.5 \mathrm{mg} / \mathrm{mL}$ suspension of levodopa/carbidopa. Its administration requires a gastrostomy for the insertion of a cannula, whose tip is placed in the duodenum. The cannula is connected to an external 
pump, which delivers the levodopa gel according to certain operator-defined parameters. Drug administration, which, generally speaking, includes a morning dose (100-200 mg in 10-30 minutes), a maintenance dose (typically $40-120 \mathrm{mg}$ hourly during the waking hours) and allows for a certain amount of rescue doses (often in the range of $10-40 \mathrm{mg}$ ), must conform to each patient's specific needs. Since its development for use in advanced PD patients [106], the clinical benefits of LCIG infusion have been reported in multiple open-label clinical trials. These studies have consistently documented a significant reduction in motor complications (including mean daily OFF time and mean daily $\mathrm{ON}$ time with troublesome dyskinesias) [107-113], a benefit on certain non-motor symptoms (such as cognition, affective symptoms, dysautonomia and pain) [113, 115], and significant improvements in quality of life [109, 110-113]. LCIG was developed and has been hitherto used mainly in Europe; only recently, large open-label studies performed in the USA have reported results that are largely in accordance to what has just been exposed [116]. Preliminary results from controlled clinical trials, so far only presented in scientific meetings, also corroborate these findings [117] and suggest that LCIG infusion positively influences quality of life in this patient group [118]. From a practical standpoint, LCIG may be considered for PD patients with severe motor fluctuations and/or disabling dyskinesia, not adequately controlled with optimal pharmacological therapy (despite a significant response to the drug), who don't have significant comorbidities or contraindications for abdominal surgery. Compared with previously discussed strategies, however, its clinical use is hindered by elevated costs, invasiveness and technical complexity [107]. Complications of the duodenal infusion of levodopa/carbidopa gel are not infrequent, but most are graded as "mild" [108-110, $113,114]$. They are usually related to the gastrostomy or, most commonly, to the device itself (including connector leakage, and dislocation or occlusion (either from kinking, knotting or coiling) of the intestinal tube). The administration of levodopa as LCIG may be associated to the whole range of complications, such as hallucinations or prominent dyskinesias, commonly associated to its administration through any other route, and prominent dyskinesias or hallucinations can also lead to discontinuation of LCIG treatment. Vitamin $\mathrm{B}_{6}$ or vitamin $\mathrm{B}_{12}$ deficiency and elevated plasma homocysteine levels $[119,120]$, which may lead to a reversible encephalopathy and/or axonal neuropathy, may occur more frequently than with oral formulations of the drug. The potential causes of this phenomenon, object of a recently published review [121], remain poorly understood. Discontinuation of treatment has ranged from 7 to $20 \%$ of treated patients in published series. It has been estimated, however, that a significant proportion (75\% after 2 years and approximately $50 \%$ at 6 years) of patients continue on this treatment modality despite the emergence of complications [122].

Various orally administered levodopa formulations and prodrugs as well as a transdermal levodopa patch are currently being developed. One of the orally administered compounds, IPX066, was studied in a cross-over design that randomized 27 patients with advanced PD to receive either IPX066 or standard levodopa for 8 days followed by administration of the other compound [122]. Patients were assessed on days 1 and 8 with regard to pharmacokinetic and clinical variables. Plasma levodopa concentrations increased at a similar rate, but were more sustained (4 vs. 1.4 hours above $50 \%$ of the peak concentration, $p<0.0001$ ) with IPX066, despite a lower dosing frequency. Data regarding tolerability and the clinical effect of the drug, however, should be cautiously interpreted, as levodopa doses given as IPX066 were higher than those given as the regular formulation. Preliminary pharmacokinetic studies with other compounds (such as XP21279, a levodopa (ND0611) transdermal patch, and inhalable levodopa) suggest that their administration is also feasible and plasma levodopa levels are relatively sustained [123-125], but further research is needed before their potential role in the clinical setting can be determined.

A complementary management strategy for motor fluctuations focuses primarily on achieving a consistent short-latency response to levodopa treatment. An orally dissolved carbidopa/levodopa preparation $\left(\right.$ Parcopa $\left.^{\mathrm{TM}}\right)$ was compared with regular levodopa/carbidopa [126]. Twenty patients with PD experiencing motor fluctuations participated in a single-dose, double-blind, double-dummy, crossover study. Patients were evaluated clinically using UPDRS score, hand tapping task and stride length at regular intervals for 1 hour and subjectively identified the onset of clinical response. Another study used the same design to evaluate potential differences between melevodopa hydrochloride/carbidopa and standard levodopa/carbidopa in 221 patients with regard to mean daily OFF time [127]. Although no statistically significant differences were found in either study, a trend towards better results with the experimental compounds was consistently identified. The significance of these findings remains to be determined. 


\section{CONCLUSIONS}

Levodopa remains the most potent dopaminergic therapy for PD. Initiating levodopa as first-line therapy may achieve optimal outcomes in terms of patient function in the early years of the disease. While the development of motor complications associated with long-term therapy is an important issue for the effective management of PD, the long-term functional benefits of the strategy of delaying levodopa therapy in favour of first-line dopamine agonists or MAO-B inhibitors are still unclear, and patients may experience symptomatic improvements smaller than those achieved with first-line levodopa therapy, even if adjunctive levodopa is subsequently introduced.

In patients who later develop response fluctuation or dyskinesias adjustment of levodopa dose, switching to alternative levodopa formulations, or supplementation of therapy with additional agents are general strategies for managing motor complications associated with levodopa. Pharmacokinetic optimization of levodopa therapy with the addition of entacapone can significantly improve the motor symptom response, a strategy that may be more effective and simpler to use than dose modification of conventional levodopa or CR formulations.

Despite the strong heritage of levodopa as the gold standard therapy for PD, the quest for a levodopa formulation that safely provides consistent brain delivery remains unsolved; nevertheless, recent advances, such as the development of LCIG, have significantly contributed towards attaining such a goal.

\section{ACKNOWLEDGMENTS}

The authors would like to thank Nadia Hashash, $\mathrm{PhD}$, for her editorial assistance, which was funded by Novartis Pharmaceuticals.

\section{DISCLOSURES}

Dr. Tolosa has been a consultant to Boehringer Ingelheim, Novartis, UCB, Solvay, Teva and Lundbeck and has received honoraria for speaking for these companies. He is the PI of Grant PI041639 from The Michael J. Fox Foundation for Parkinson Disease (ASymptomatic G2019S/R1441G LRRK2 mutation carriers and Assessment of factors influencing LRRK2-related PD expression study).

\section{CONFLICT OF INTEREST}

Dr. Salat has no conflict of interest to report.

\section{REFERENCES}

[1] Pirker W (2003) Correlation of dopamine transporter imaging with parkinsonian motor handicap: How close is it? Mov Disord, 18(Suppl 7), S43-S51.

[2] Fearnley JM, \& Lees AJ (1991) Ageing and Parkinson's disease: Substantia nigra regional selectivity. Brain, 114, 2283-2301.

[3] Damier P, Hirsch EC, Agid Y, \& Graybiel AM (1999) The substantia nigra of the human brain. II. Patterns of loss of dopamine-containing neurons in Parkinson's disease. Brain, 122 (Pt 8), 1437-1448.

[4] Tolosa E, Gaig C, Santamaria J, \& Compta Y (2009) Diagnosis and the premotor phase of Parkinson disease. Neurology, 72, S12-S20.

[5] Hughes AJ, Daniel SE, Kilford L, \& Lees AJ (1992) Accuracy of clinical diagnosis of idiopathic Parkinson's disease: A clinico-pathological study of 100 cases. J Neurol Neurosurg Psychiatry, 55, 181-184.

[6] Poewe W (2009) Clinical measures of progression in Parkinson's disease. Mov Disord, 24(Suppl 2), S671-S676.

[7] Fahn S (2005) Does levodopa slow or hasten the rate of progression of Parkinson's disease? J Neurol, 252, iv37iv42.

[8] Sethi KD (2010) The impact of levodopa on quality of life in patients with Parkinson disease. Neurologist, 16, 76-83.

[9] Grandas F, Martinez-Martin P, \& Linazasoro G (1998) Quality of life in patients with Parkinson's disease who transfer from standard levodopa to Sinemet CR: The STAR Study. The STAR Multicenter Study Group. J Neurol, 245(Suppl 1), S31-S33.

[10] Cotzias GC (1969) Parkinsoism and Dopa. J Chronic Dis, 22, 297-301.

[11] Agid Y, Olanow CW, \& Mizuno Y (2002) Levodopa: Why the controversy? Lancet, 360, 575.

[12] Papavasiliou PS, Cotzias GC, Duby SE, Steck AJ, Fehling C, \& Bell MA (1972) Levodopa in Parkinsonism: Potentiation of central effects with a peripheral inhibitor. $N$ Engl J Med, 286, 8-14.

[13] Birkmayer W, \& Mentasti M (1967) [Further experimental studies on the catecholamine metabolism in extrapyramidal diseases (Parkinson and chorea syndromes)]. Arch Psychiatr Nervenkr, 210, 29-35.

[14] Huebert ND, Palfreyman MG, \& Haegele KD (1983) A comparison of the effects of reversible and irreversible inhibitors of aromatic L-amino acid decarboxylase on the half-life and other pharmacokinetic parameters of oral L-3,4-dihydroxyphenylalanine. Drug Metab Dispos, 11, 195-200.

[15] Cedarbaum JM, Kutt H, \& McDowell FH (1989) A pharmacokinetic and pharmacodynamic comparison of Sinemet CR (50/200) and standard Sinemet (25/100). Neurology, 39, 38-44; discussion 59.

[16] MacMahon DG, Sachdev D, Boddie HG, Ellis CJ, Kendal BR, \& Blackburn NA (1990) A comparison of the effects of controlled-release levodopa (Madopar CR) with conventional levodopa in late Parkinson's disease. J Neurol Neurosurg Psychiatry, 53, 220-223. 
[17] Sage JI, \& Mark MH (1994) Pharmacokinetics of continuous-release carbidopa/levodopa. Clin Neuropharmacol, 17(Suppl 2), S1-S6.

[18] Benetello P, Furlanut M, Fortunato M, Pea F, \& Baraldo M (1997) Levodopa and 3-O-methyldopa in cerebrospinal fluid after levodopa-carbidopa association. Pharmacol Res, 35, 313-315.

[19] Gauthier S, \& Amyot D (1992) Sustained release antiparkinson agents: Controlled release levodopa. Can J Neurol Sci, 19, 153-155.

[20] Wolters EC, \& Tesselaar HJM (1996) International (NKUK) double-blind study of sinemet CR and standard sinemet $(25 / 100)$ in 170 patients with fluctuating Parkinson's disease. Journal of Neurology, 243, 235-240.

[21] Block G, Liss C, Reines S, Irr J, \& Nibbelink D (1997) Comparison of immediate-release and controlled release carbidopa/levodopa in Parkinson's disease. A multicenter 5-year study. The CR First Study Group. Eur Neurol, 37, 23-27.

[22] Jankovic J, Schwartz K, \& Vander Linden C (1989) Comparison of Sinemet CR4 and standard Sinemet: Double blind and long-term open trial in parkinsonian patients with fluctuations. Mov Disord, 4, 303-309.

[23] Goetz CG, Tanner CM, Shannon KM, Carroll VS, Klawans HL, Carvey PM, \& Gilley D (1988) Controlled-release carbidopa/levodopa (CR4-Sinemet) in Parkinson's disease patients with and without motor fluctuations. Neurology, 38, 1143-1146.

[24] Koller WC, Hutton JT, Tolosa E, \& Capilldeo R (1999) Immediate-release and controlled-release carbidopa/levodopa in PD: A 5-year randomized multicenter study. Carbidopa/Levodopa Study Group. Neurology, 53, 1012-1019.

[25] Kaakkola S, Teravainen H, Ahtila S, Rita H, \& Gordin A (1994) Effect of entacapone, a COMT inhibitor, on clinical disability and levodopa metabolism in parkinsonian patients. Neurology, 44, 77-80.

[26] Gordin A, Kaakkola S, \& Teravainen H (2004) Clinical advantages of COMT inhibition with entacapone - a review. J Neural Transm, 111, 1343-1363.

[27] Parkinson Study Group (1997) Entacapone improves motor fluctuations in levodopa-treated Parkinson's disease patients. Ann Neurol, 42, 747-755.

[28] Rinne UK, Larsen JP, Siden A, \& Worm-Petersen J (1998) Entacapone enhances the response to levodopa in parkinsonian patients with motor fluctuations. NOMECOMT Study Group. Neurology, 51, 1309-1314.

[29] Poewe WH, Deuschl G, Gordin A, Kultalahti ER, \& Leinonen M (2002) Efficacy and safety of entacapone in Parkinson's disease patients with suboptimal levodopa response: A 6-month randomized placebo-controlled double-blind study in Germany and Austria (Celomen study). Acta Neurol Scand, 105, 245-255.

[30] Brooks DJ, \& Sagar H (2003) Entacapone is beneficial in both fluctuating and non-fluctuating patients with Parkinson's disease: A randomised, placebo controlled, double blind, six month study. J Neurol Neurosurg Psychiatry, 74, 1071-1079.

[31] Stocchi F, Rascol O, Kieburtz K, Poewe W, Jankovic J, Tolosa E, Barone P, Lang AE, \& Olanow CW (2010) Initiating levodopa/carbidopa therapy with and without entacapone in early Parkinson disease: The STRIDE-PD study. Ann Neurol, 68, 18-27.

[32] Stowe R, Ives N, Clarke CE, Handley K, Furmston A, Deane K, van Hilten JJ, Wheatley K \& Gray R (2011) Meta-analysis of the comparative efficacy and safety of adjuvant treatment to levodopa in later Parkinson's disease. Mov Disord, 26, 587-598.

[33] Antonini A, Abbruzzese G, Barone P, Bonuccelli U, Lopiano L, Onofrj M, Zappia M, \& Quattrone A (2008) COMT inhibition with tolcapone in the treatment algorithm of patients with Parkinson's disease (PD): Relevance for motor and non-motor features. Neuropsychiatr Dis Treat, 4, 1-9.

[34] Kiss LE, Ferreira HS, Torrao L, Bonifacio MJ, Palma PN, Soares-da-Silva P, \& Learmonth DA (2010) Discovery of a long-acting, peripherally selective inhibitor of catechol-Omethyltransferase. J Med Chem, 53, 3396-3411.

[35] Tolosa ES, Martin WE, Cohen HP, \& Jacobson RL (1975) Patterns of clinical response and plasma dopa levels in Parkinson's disease. Neurology, 25, 177-183.

[36] Muenter MD, \& Tyce GM (1971) L-dopa therapy of Parkinson's disease: Plasma L-dopa concentration, therapeutic response, and side effects. Mayo Clin Proc, 46, 231-239.

[37] Melamed E (1979) Early-morning dystonia. A late side effect of long-term levodopa therapy in Parkinson's disease. Arch Neurol, 36, 308-310.

[38] Poewe WH, Lees AJ, \& Stern GM (1988) Dystonia in Parkinson's disease: Clinical and pharmacological features. Ann Neurol, 23, 73-78.

[39] Witjas T, Kaphan E, Azulay JP, Blin O, Ceccaldi M, Pouget J, Poncet M, \& Cherif AA (2002) Nonmotor fluctuations in Parkinson's disease: Frequent and disabling. Neurology, 59, 408-413.

[40] Stacy M, Bowron A, Guttman M, Hauser R, Hughes K, Larsen JP, Lewitt P, Oertel W, Quinn N, Sethi K, \& Stocchi F (2005) Identification of motor and nonmotor wearing-off in Parkinson's disease: Comparison of a patient questionnaire versus a clinician assessment. Mov Disord, 20, 726-733.

[41] de la Fuente-Fernandez R, Lu JQ, Sossi V, Jivan S, Schulzer M, Holden JE, Lee CS, Ruth TJ, Calne DB, \& Stoessl AJ (2001) Biochemical variations in the synaptic level of dopamine precede motor fluctuations in Parkinson's disease: PET evidence of increased dopamine turnover. Ann Neurol, 49, 298-303.

[42] de la Fuente-Fernandez R, Sossi V, Huang Z, Furtado S, Lu JQ, Calne DB, Ruth TJ, \& Stoessl AJ (2004) Levodopainduced changes in synaptic dopamine levels increase with progression of Parkinson's disease: Implications for dyskinesias. Brain, 127, 2747-2754.

[43] Chase TN (1998) The significance of continuous dopaminergic stimulation in the treatment of parkinson's disease. Drugs, 55, 1-9.

[44] Obeso JA, Rodriguez-Oroz MC, Rodriguez M, DeLong MR, \& Olanow CW (2000) Pathophysiology of levodopainduced dyskinesias in Parkinson's disease: Problems with the current model. Ann Neurol, 47, S22-32; discussion S3224.

[45] Cenci MA (2007) Dopamine dysregulation of movemen control in L-DOPA-induced dyskinesia. Trends Neurosci, 30, 236-243.

[46] Stocchi F (2010) The concept of continuous dopaminergic stimulation: What we should consider when starting Parkinson's disease treatment. Neurodegener Dis, 7, 213-215.

[47] Fahn S, Oakes D, Shoulson I, Kierburtz K, Rudolph A, Lang A, Olanow W, \& Marek K (2004) Levodopa and the progression of Parkinson's disease. N Engl J Med, 351, 24982508.

[48] Kumar N, Van Gerpen JA, Bower JH, \& Ahlskog JE (2005) Levodopa-dyskinesia incidence by age of Parkinson's disease onset. Mov Disord, 20, 342-344. 
[49] Quinn N, Critchley P, \& Marsden CD (1987) Young onset Parkinson's disease. Mov Disord, 2, 73-91.

[50] Ahlskog JE, \& Muenter MD (2001) Frequency of levodoparelated dyskinesias and motor fluctuations as estimated from the cumulative literature. Mov Disord, 16, 448-458.

[51] Castro-Garcia A (1997) [Psychiatric complications of L-dopa: Physiopathology and treatment]. Rev Neurol, 25(Suppl 2), S157-S162.

[52] Vilas D, Pont-Sunyer C, \& Tolosa E (2012) Impulse control disorders in Parkinson's disease. Parkinsonism Relat Disord, 18(Suppl 1), S80-84.

[53] Weintraub D, Koester J, Potenza MN, Siderowf AD, Stacy M, Voon V, Whetteckey J, Wunderlich GR, \& Lang AE (2010) Impulse control disorders in Parkinson disease: A cross-sectional study of 3090 patients. Arch Neurol, 67, 589595.

[54] Molina JA, Sainz-Artiga MJ, Fraile A, Jimenez-Jimenez FJ, Villanueva C, Orti-Pareja M, \& Bermejo F (2000) Pathologic gambling in Parkinson's disease: A behavioral manifestation of pharmacologic treatment? Mov Disord, 15, 869872.

[55] van Deelen RA, Rommers MK, Eerenberg JG \& Egberts AC (2002) [Hypersexuality during use of levodopa]. Ned Tijdschr Geneeskd, 146, 2095-2098.

[56] O'Sullivan SS, Evans AH, \& Lees AJ (2009) Dopamine dysregulation syndrome: An overview of its epidemiology, mechanisms and management. CNS Drugs, 23, 157-170.

[57] Evans AH, Pavese N, Lawrence AD, Tai YF, Appel S, Doder M, Brooks DJ, Lees AJ, \& Piccini P (2006) Compulsive drug use linked to sensitized ventral striatal dopamine transmission. Ann Neurol, 59, 852-858.

[58] Pezzella FR, Colosimo C, Vanacore N, Di Rezze S, Chianese M, Fabbrini G, \& Meco G (2005) Prevalence and clinical features of hedonistic homeostatic dysregulation in Parkinson's disease. Mov Disord, 20, 77-81.

[59] Evans AH, Lawrence AD, Potts J, Appel S, \& Lees AJ (2005) Factors influencing susceptibility to compulsive dopaminergic drug use in Parkinson disease. Neurology, 65, 1570-1574.

[60] Spencer AH, Rickards H, Fasano A, \& Cavanna AE (2011) The prevalence and clinical characteristics of punding in Parkinson's disease. Mov Disord, 26, 578-586.

[61] Fasano A, Ricciardi L, Pettorruso M, \& Bentivoglio AR (2011) Management of punding in Parkinson's disease: An open-label prospective study. J Neurol, 258, 656-660.

[62] Broen M, Duits A, Visser-Vandewalle V, Temel Y, \& Winogrodzka A (2011) Impulse control and related disorders in Parkinson's disease patients treated with bilateral subthalamic nucleus stimulation: A review. Parkinsonism Relat Disord, 17, 413-417.

[63] Oertel WH, Berardelli A, Bloem BR, Bonuccelli U, Burn D, Deuschl G, Dietrichs E, Fabbrini G, Ferreira JJ, Friedman A, Kanovsky P, Kostic V, Nieuwboer A, Odin P, Poewe W, Rascol O, Sampaio C, Schüpbach M, Tolosa E, \& Trenkwalder C (2010) Chapter 15: Late (complicated) Parkinson's disease. In: Nils Erik Gilhus, Michael R. Barnes, Brainin M, editors, European Handbook of Neurological Management, Wiley-Blackwell, p. 584.

[64] Au WL, Adams JR, Troiano AR, \& Stoessl AJ (2005) Parkinson's disease: In vivo assessment of disease progression using positron emission tomography. Brain Res Mol Brain Res, 134, 24-33.

[65] Fox SH, Katzenschlager R, Lim SY, Ravina B, Seppi K, Coelho M, Poewe W, Rascol O, Goetz CG, \& Sampaio C (2011) The Movement Disorder Society Evidence-Based
Medicine Review Update: Treatments for the motor symptoms of Parkinson's disease. Mov Disord, 26(Suppl 3), $\mathrm{S} 2-\mathrm{S} 41$.

[66] Seppi K, Weintraub D, Coelho M, Perez-Lloret S, Fox SH, Katzenschlager R, Hametner EM, Poewe W, Rascol O, Goetz CG, \& Sampaio C (2011) The Movement Disorder Society Evidence-Based Medicine Review Update: Treatments for the non-motor symptoms of Parkinson's disease. Mov Disord, 26(Suppl 3), S42-S80.

[67] The National Collaborating Centre for Chronic Conditions. Parkinson's disease: National clinical guideline for diagnosis and management in primary and secondary care. Royal College of Physicians, London, 2006.

[68] Hauser RA, Rascol O, Korczyn AD, Jon Stoessl A, Watts RL, Poewe W, De Deyn PP, \& Lang AE (2007) Ten-year follow-up of Parkinson's disease patients randomized to initial therapy with ropinirole or levodopa. Mov Disord, 22, 2409-2417.

[69] Lees AJ, Katzenschlager R, Head J, \& Ben-Shlomo Y (2001) Ten-year follow-up of three different initial treatments in de-novo PD: A randomized trial. Neurology, 57, 16871694.

[70] Jankovic J (2001) Parkinson's disease therapy: Treatment of early and late disease. Chin Med J (Engl), 114, 227-234.

[71] Antonini A, Tolosa E, Mizuno Y, Yamamoto M, \& Poewe WH (2009) A reassessment of risks and benefits of dopamine agonists in Parkinson's disease. Lancet Neurol, 8, 929937.

[72] Hauser RA, Panisset M, Abbruzzese G, Mancione L, Dronamraju N, \& Kakarieka A (2009) Double-blind trial of levodopa/carbidopa/entacapone versus levodopa/carbidopa in early Parkinson's disease. Mov Disord, 24, 541-550.

[73] Barone P, Poewe W, Albrecht S, Debieuvre C, Massey D, Rascol O, Tolosa E, \& Weintraub D (2010) Pramipexole for the treatment of depressive symptoms in patients with Parkinson's disease: A randomised, double-blind, placebocontrolled trial. Lancet Neurol, 9, 573-580.

[74] Stocchi F, Barbato L, Nordera G, Berardelli A, \& Ruggieri S (1998) Sleep disorders in Parkinson's disease. J Neurol, 245(Suppl 1), S15-S18

[75] Tan A, Salgado M, \& Fahn S (1996) Rapid eye movement sleep behavior disorder preceding Parkinson's disease with therapeutic response to levodopa. Mov Disord, 11, 214216.

[76] Iranzo A, Molinuevo JL, Santamaria J, Serradell M, Marti MJ, Valldeoriola F, \& Tolosa E (2006) Rapid-eye-movement sleep behaviour disorder as an early marker for a neurodegenerative disorder: A descriptive study. Lancet Neurol, 5, 572-577.

[77] Schestatsky P, Kumru H, Valls-Sole J, Valldeoriola F, Marti MJ, Tolosa E, \& Chaves ML (2007) Neurophysiologic study of central pain in patients with Parkinson disease. Neurology, 69, 2162-2169.

[78] Schifitto G, Friedman JH, Oakes D, Shulman L, Comella CL, Marek K, Fahn S, \& Parkinson Study Group EI (2008) Fatigue in levodopa-naive subjects with Parkinson disease. Neurology, 71, 481-485.

[79] Fetoni V, Soliveri P, Monza D, Testa D \& Girotti F (1999) Affective symptoms in multiple system atrophy and Parkinson's disease: Response to levodopa therapy. J Neurol Neurosurg Psychiatry, 66, 541-544.

[80] Eskow Jaunarajs KL, Angoa-Perez M, Kuhn DM, \& Bishop C (2011) Potential mechanisms underlying anxiety and depression in Parkinson's disease: Consequences of 1-DOPA treatment. Neurosci Biobehav Rev, 35, 556-564. 
[81] Molloy SA, Rowan EN, O’Brien JT, McKeith IG, Wesnes K, \& Burn DJ (2006) Effect of levodopa on cognitive function in Parkinson's disease with and without dementia and dementia with Lewy bodies. J Neurol Neurosurg Psychiatry, 77, 1323-1328.

[82] Lange KW, Robbins TW, Marsden CD, James M, Owen AM \& Paul GM (1992) L-dopa withdrawal in Parkinson's disease selectively impairs cognitive performance in tests sensitive to frontal lobe dysfunction. Psychopharmacology (Berl), 107, 394-404.

[83] Gotham AM, Brown RG \& Marsden CD (1988) 'Frontal' cognitive function in patients with Parkinson's disease 'on' and 'off' levodopa. Brain, 111(Pt 2), 299-321.

[84] Pascual-Sedano B, Kulisevsky J, Barbanoj M, GarciaSanchez C, Campolongo A, Gironell A, Pagonabarraga J, \& Gich I (2008) Levodopa and executive performance in Parkinson's disease: A randomized study. J Int Neuropsychol Soc, 14, 832-841.

[85] Gershanik OS (2010) Clinical problems in late-stage Parkinson's disease. J Neurol, 257, S288-S291.

[86] Harder S, \& Baas H (1998) Concentration-response relationship of levodopa in patients at different stages of Parkinson's disease. Clin Pharmacol Ther, 64, 183-191.

[87] Politis M, Wu K, Molloy S, P GB, Chaudhuri KR, \& Piccini P (2010) Parkinson's disease symptoms: The patient's perspective. Mov Disord, 25, 1646-1651.

[88] Hattori N, Fujimoto K, Kondo T, Murata M, \& Stacy M (2010) Patient perspectives towards levoodpa therapy in Japan and the United States - results of two patient surveys. Mov Disord, 25, S569-S717.

[89] Stocchi F (2006) The levodopa wearing-off phenomenon in Parkinson's disease: Pharmacokinetic considerations. Expert Opin Pharmacother, 7, 1399-1407.

[90] Wullner U, Fuchs G, Reketat N, Randerath O, \& Kassubek J (2012) Requirements for Parkinson's disease pharmacotherapy from the patients' perspective: A questionnaire-based survey. Curr Med Res Opin, 28, 1239-1246.

[91] Pahwa R, Lyons K, McGuire D, Dubinsky R, Hubble JP, \& Koller WC (1996) Early morning akinesia in Parkinson's disease: Effect of standard carbidopa/levodopa and sustained-release carbidopa/levodopa. Neurology, 46, 10591062.

[92] Grosset KA, Reid JL, \& Grosset DG (2005) Medicine-taking behavior: Implications of suboptimal compliance in Parkinson's disease. Mov Disord, 20, 1397-1404.

[93] Koller WC, \& Pahwa R (1994) Treating motor fluctuations with controlled-release levodopa preparations. Neurology, 44, S23-28.

[94] Muller T, Erdmann C, Muhlack S, Bremen D, Przuntek H, Goetze O, \& Woitalla D (2006) Pharmacokinetic behaviour of levodopa and 3-O-methyldopa after repeat administration of levodopa/carbidopa with and without entacapone in patients with Parkinson's disease. J Neural Transm, 113, 1441-1448.

[95] Brooks DJ, Agid Y, Ostergaard JR, Widner H, \& Oertel W (2003) A new triple combination tablet is easy to initiate and provides symptom control in patients with Parkinson's disease. Eur J Neurol, 10(Suppl 1), 241 (Abstract).

[96] Ingman K, Naukkarinen T, Vahteristo M, Korpela I, Kuoppamaki M, \& Ellmen J (2012) The effect of different dosing regimens of levodopa/carbidopa/entacapone on plasma levodopa concentrations. Eur J Clin Pharmacol, 68, 281289.

[97] Kuoppamäki M, Sauramo A, Korpela K, Vahteristo M, Kailajärvi M, Lehtinen T, \& Ellmén J (2010) Night-time bioavailability of levodopa/carbidopa/entacapone is higher compared with controlled-release levodopa/carbidopa. Int $J$ Clin Pharmacol and Ther 48, 756-760.

[98] Sauramo A, Korpela K, Vahteristo M, Kuoppamaki M, Kailiajarvi M, Lehtinen T, Ellmen J, \& Nissinen H (2008) Pharmacokinetic profile of levodopa after a single night-time dose or after repeated daily dosing of levodopa/carbidopa/entacapone 200/50/200mg (Stalevo ${ }^{\circledR}$ ) compared with controlled-release levodopa/carbidopa 200/50mg (Sinemet ${ }^{\circledR}$ CR) in healthy volunteers. Ann Neurol, 64, S1-S139 (Abstract T-171).

[99] Verhagen Metman L, Del Dotto P, van den Munckhof P, Fang J, Mouradian MM, \& Chase TN (1998) Amantadine as treatment for dyskinesias and motor fluctuations in Parkinson's disease. Neurology, 50, 1323-1326.

[100] Snow BJ, Macdonald L, McAuley D, \& Wallis W (2000) The effect of amantadine on levodopa-induced dyskinesias in Parkinson's disease: A double-blind, placebo-controlled study. Clin Neuropharmacol, 23, 82-85.

[101] Durif F, Debilly B, Galitzky M, Morand D, Viallet F, Borg M, Thobois S, Broussolle E, \& Rascol O (2004) Clozapine improves dyskinesias in Parkinson disease: A double-blind, placebo-controlled study. Neurology, 62, 381-388.

[102] Katzenschlager R, Manson AJ, Evans A, Watt H, \& Lees AJ (2004) Low dose quetiapine for drug induced dyskinesias in Parkinson's disease: A double blind cross over study. J Neurol Neurosurg Psychiatry, 75, 295-297.

[103] Cenci MA, Ohlin KE, \& Odin P (2011) Current options and future possibilities for the treatment of dyskinesia and motor fluctuations in Parkinson's disease. CNS Neurol Disord Drug Targets, 10, 670-684.

[104] Quinn N, \& Marsden CD (1986) Lithium for painful dystonia in Parkinson's disease. Lancet, 1, 1377

[105] Pacchetti C, Albani G, Martignoni E, Godi L, Alfonsi E, \& Nappi G (1995) "Off” painful dystonia in Parkinson's disease treated with botulinum toxin. Mov Disord, 10, 333336.

[106] Bredberg E, Nilsson D, Johansson K, Aquilonius SM, Johnels B, Nyström C, \& Paalzow L (1993) Intraduodenal infusion of a water-based levodopa dispersion for optimisation of the therapeutic effect in severe Parkinson's disease. Eur J Clin Pharmacol, 45, 117-122.

[107] Syed N, Murphy J, Zimmerman T, Jr., Mark MH, \& Sage JI (1998) Ten years' experience with enteral levodopa infusions for motor fluctuations in Parkinson's disease. Mov Disord, 13, 336-338.

[108] Nilsson D, Nyholm D, \& Aquilonius SM (2001) Duodenal levodopa infusion in Parkinson's disease-long-term experience. Acta Neurol Scand, 104, 343-348.

[109] Antonini A, Isaias IU, Canesi M, Zibetti M, Mancini F, Manfredi L, Dal Fante M, Lopiano L, \& Pezzoli G (2007) Duodenal levodopa infusion for advanced Parkinson's disease: 12-month treatment outcome. Mov Disord, 22, 1145-1149.

[110] Devos D on behalf of the French DUODOPA Study Group (2009) Patient profile, indications, efficacy and safety of duodenal levodopa infusion in advanced Parkinson's disease. Mov Disord, 24, 993-1000.

[111] Puente V, De Fabregues O, Oliveras C, Ribera G, PontSunyer C, Vivanco R, Cucurella G, Giralt E, Delgado T, Garcia C, Seoane A, \& Campo R (2010) Eighteen month study of continuous intraduodenal levodopa infusion in patients with advanced Parkinson's disease: Impact on control of fluctuations and quality of life. Parkinsonism Relat Disord, 16, 218-221. 
[112] Fasano A, Ricciardi L, Lena F, Bentivoglio AR, \& Modugno N (2012) Intrajejunal levodopa infusion in advanced Parkinson's disease: Long-term effects on motor and nonmotor symptoms and impact on patient's and caregiver's quality of life. Eur Rev Med Pharmacol Sci, 16, 79-89.

[113] Nyholm D (2012) Duodopa(R) treatment for advanced Parkinson's disease: A review of efficacy and safety. Parkinsonism Relat Disord, 18, 916-929.

[114] Nyholm D, Lewander T, Johansson A, Lewitt PA, Lundqvist C, \& Aquilonius SM (2008) Enteral levodopa/carbidopa infusion in advanced Parkinson disease: Long-term exposure. Clin Neuropharmacol, 31, 63-73.

[115] Honig H, Antonini A, Martinez-Martin P, Forgacs I, Faye GC, Fox T, Fox K, Mancini F, Canesi M, Odin P, \& Chaudhuri KR (2009) Intrajejunal levodopa infusion in Parkinson's disease: A pilot multicenter study of effects on nonmotor symptoms and quality of life. Mov Disord, 24, 1468-1474.

[116] Fernandez HH, Vanagunas A, Odin P, Espay AJ, Hauser RA, Standaert DG, Chatamra K, Benesh J, Pritchett Y, Hass SL, \& Lenz RA (2013) Levodopa-carbidopa intestinal gel in advanced Parkinson's disease open-label study: Interim results. Parkinsonism Relat Disord, 19, 339-345.

[117] Olanow CW, Antonini A, Kieburtz K, Fernandez HH, Espay AJ, Standaert DG, \& Vanagunas AD (2012) Randomized, double-blind, double-dummy study of continuous infusion of levodopa-carbidopa intestinal gel in patients with advanced Parkinson's disease: Efficacy and safety [abstract]. Mov Disord, 27(Suppl 1), 411.

[118] Kieburtz K, Antonini A, Olanow CW, Fernandez HH, Espay AJ, Standaert DG, \& Hass S (2012) Randomized, phase 3 , double-blind, double-dummy study of levodopa-carbidopa intestinal gel in patients with advanced Parkinson's disease: Functional and quality-of-life outcomes [abstract]. Mov Disord, 27(Suppl 1), 385.

[119] Urban PP, Wellach I, Faiss S, Layer P, Rosenkranz T, Knop K, \& Weis J (2010) Subacute axonal neuropathy in Parkinson's disease with cobalamin and vitamin B6 deficiency under duodopa therapy. Mov Disord, 25, 1748-1752.
[120] Muller T, Jugel C, Ehret R, Ebersbach G, Bengel G, Muhlack S, \& Klostermann F (2011) Elevation of total homocysteine levels in patients with Parkinson's disease treated with duodenal levodopa/carbidopa gel. J Neural Transm, 118, 1329-1333.

[121] Müller T, Laar Tv, Cornblath DR, Odin P, Klostermann F, Grandas FJ, Ebersbach G, Urban PP, Valldeoriola F, \& Antonini A (2013) Peripheral neuropathy in Parkinson's disease: Levodopa exposure and implications for duodenal delivery. Parkinsonism Relat Disord, 19, 501-507.

[122] Hauser RA, Ellenbogen AL, Metman LV, Hsu A, O'Connell MJ, Modi NB, Yao HM, Kell SH, \& Gupta SK (2011) Crossover comparison of IPX066 and a standard levodopa formulation in advanced Parkinson's disease. Mov Disord, 26, 2246-2252.

[123] Hauser RA (2011) Future treatments for Parkinson's disease: Surfing the PD pipeline. Int J Neurosci, 121(Suppl 2), 53-62.

[124] Di Stefano A, Sozio P, Cerasa LS, \& Iannitelli A (2011) L-Dopa prodrugs: An overview of trends for improving Parkinson's disease treatment. Curr Pharm Des, 17, 34823493.

[125] Sudo J, Iwase H, Higashiyama K, Kakuno K, Miyasaka F, Meguro T, \& Takayama K (2002) Elevation of plasma levels of L-dopa in transdermal administration of L-dopabutylester in rats. Drug Dev Ind Pharm, 28, 59-65.

[126] Ondo WG, Shinawi L, \& Moore S (2010) Comparison of orally dissolving carbidopa/levodopa (Parcopa) to conventional oral carbidopa/levodopa: A single-dose, double-blind, double-dummy, placebo-controlled, crossover trial. Mov Disord, 25, 2724-2727.

[127] Stocchi F, Zappia M, Dall'Armi V, Kulisevsky J, Lamberti P, Obeso JA, \& Melevodopa Plus Carbidopa Study G (2010) Melevodopa/carbidopa effervescent formulation in the treatment of motor fluctuations in advanced Parkinson's disease. Mov Disord, 25, 1881-1887. 